\title{
Building responsive bio-economic models to replicate complex farm management decisions for mixed irrigation farming systems in southern NSW
}

\author{
$\underline{\text { K. Broadfoot }}^{\mathrm{a}}$, M. Cashen ${ }^{\mathrm{b}}$. K. Behrendt ${ }^{\mathrm{cd}}$, A.J. Clark ${ }^{\mathrm{a}}$ and P. Graham ${ }^{\mathrm{e}}$ \\ ${ }^{a}$ NSW Department of Primary Industries, Orange Agricultural Institute, 1447 Forest Road, Orange, NSW, ${ }^{b}$ \\ NSW Department of Primary Industries, Wagga Wagga Agricultural Institute, 322 Pine Gully Rd, Wagga \\ Wagga, NSW 2800, ' Graham Centre for Agricultural Innovation, Wagga Wagga, NSW 2800, ${ }^{d}$ Harper \\ Adams University, Edgmond, Shropshire, UK, TF10 8NB, ${ }^{e}$ Graham Advisory, 78 Obrien St Yass, NSW, \\ 2582.Email:kim.broadfoot@dpi.nsw.gov.au
}

\begin{abstract}
This paper is part of a broader study that uses AusFarm, a complex biophysical model, to model a mixed irrigation farming system in the Murray Irrigation Area and Districts (Murray Irrigation Limited (MIL) post 1995). The study is unique is that the biophysical model has been coupled to an economic module that includes an irrigation sequence model and pricing function. The study has enabled the examination of water market tools that irrigators have available to them in the MIL ('temporary water' and 'carry over'), and the importance of these tool in managing future risk under changing climates.

This paper shows that a combination of water market tools will be an important component in managing risk under changing climate, at least under a mid-range emissions scenario with modest reductions in irrigation water availability. For example, the modelling in this paper shows that having both the ability to carry over water to the following water year, and access to temporary water markets increases the likelihood of sowing opportunities and yield gains for the summer irrigated crop for both historical and projected climate periods. Access to these tools will become crucial as irrigators manage future water supply and demand risk under the impact of climate change and changes to water policy.
\end{abstract}

Keywords: AusFarm, climate change in agriculture, agricultural systems modelling 


\section{INTRODUCTION}

Irrigation in the Southern Riverina of New South Wales was initially developed as 'drought proofing' to provide reliable stock and domestic water to low rainfall areas that cover around 800000 ha around the NSW towns of Deniliquin, Finley and Wakool. Historically irrigators in the region have enjoyed high water security which has enabled a diversity of agricultural industries to flourish. However, the decline in water availability in the MIL is being keenly felt by the region's agriculture sector and dependent regional communities.

Access to water market tools has been instrumental for farm irrigation management and planning in the area serviced by the Murray Irrigation Area and Districts (Murray Irrigation Limited (MIL) post 1995). By having the ability to purchase 'temporary water' on the open market and utilise the option for 'carry over' water, irrigators have been able to increase the likelihood of being able to sow and maximise the yield of their crops. A key mechanism available to irrigators in the concept of a cap and trade system. This system, regulated by Government, determines annual water determinations (AWD's; referred to as 'water allocations' in this paper) and informs Water Access Licence (WAL) holders how much water they can extract.

Water allocations are redetermined during the water year (1st July- 30th June) depending on water resource availability. WAL's can be traded permanently or on an annual basis (temporary trade licence) and producers can use the market to sell or buy temporary water. Additionally, producers have access to an additional management tool under the current framework; that is the ability to carry over $50 \%$ of their entitlement volume to the following water year. Although there are restrictions placed on the volume of water that a producer can carry forward to the following year (Murray Irrigation 2014).

This paper is part of a broader study where AusFarm was used to investigate the influence of water market tools on an irrigated mixed farming system in southern NSW. The study was the first of its kind, were a rice cropping module was integrated into the AusFarm framework. Additionally, novel methodologies were developed to allow farm management decisions to be coupled with water allocations through a purpose-built economic module. This paper focuses on one component of the broader study, by investigating the influence of existing water market tools on the summer irrigated rice crop for a mixed irrigation farming system in southern NSW, and the importance of these tool in offsetting or mitigating the impacts of future climate. The paper explores the influence of the water market tool on the frequency of sowing opportunities for summer crops (i.e. rice or maize) and the subsequent effect this has on crop yield.

\section{METHODS}

To simulate the influence of water market tools in farm decision making, several extensions to an existing AusFarm $^{\mathrm{TM}}$ (Moore et al. 2007) modelling framework needed to be developed. Firstly, the biophysical model needed to be developed to include an irrigated rice cropping module and associated management decisions. Secondly, an irrigation allocation sequence needed to be incorporated into the biophysical model to drive irrigation scheduling decisions. Thirdly, an economic module was built into AusFarm, which consisted of a water market price function, in order to assess the influence of water market tools. Lastly, once a water market price function was developed, management decisions to utilise available water market tools needed to be developed based on common farm management practices in the region.

\subsection{Biophysical model development}

Commonwealth Scientific and Industrial Research Organisation's (CSIRO) AusFarm ${ }^{\mathrm{TM}}$ model (version No. 1.4.13) was used for this study as it enables integration of the GrassGro ${ }^{\text {TM }}$ (Freer et al. 1997; Moore et al. 1997) and APSIM (Keating et al. 2003; McCowan et al. 1995) modules, while providing additional functionality to enable tailoring of the model to be representative of the farming system and associated management decision making. AusFarm operates on a daily timestep where in addition to simulating biophysical performance, modules can be built to represent the management structure and decisions in complex mixed farms. However, it should be noted that AusFarm, like other similar models, does not adequately represent disease (plant or animal) or the impacts of pest species, and as such tend to overstate biophysical performance.

\subsection{Farming system assumptions}

AusFarm was used to develop a representative mixed irrigated farming system in the Murray Valley, near Finley $\left(35.64^{\circ} \mathrm{S}, 145.57^{\circ} \mathrm{E}\right)$, New South Wales. The farm consisted of 9 paddocks, with a summer and winter cropping program. Eight paddocks (60ha each) were part of the irrigation component of the farming system and one paddock was configured as dryland cropping (220ha). The irrigated rotation system was rice, fallow, 
Broadfoot et al., Building responsive bio-economic models...

irrigated wheat, irrigated canola, irrigated wheat, irrigated canola, non-irrigated wheat and non-irrigated canola. The dryland rotation system was wheat, barley and canola.

Site selection was based on the availability of soil datasets in the region using the Australian Soil Resource Information System (ASRIS) (CSIRO 2013). The soil chosen was Berrigan No.537-YP. Fertiliser assumptions in the AusFarm model were set in line with industry recommendations with adjustments made to ensure crop yields met regional expectations (see 2.7). Crop variety was selected based on the most suitable cultivars available in the AusFarm.

The biophysical model was set up to apply irrigation water based on a set of management rules. For the summer crop, rice was able to receive irrigation water between the 26 September and 25 February, in the form of ponding to initiate germination, plant establishment and the temperature sensitive flowering period. Irrigation was applied when water depth dropped below $600 \mathrm{~mm}$ (assessed every two days) above ground level (to simulate a ponded rice crop). Winter crops, that could be potentially irrigated), were scheduled to receive irrigation on 25 April and 4 August (for wheat) or on 5 April and 2 August (for canola). Irrigation water was applied if the water balance was in surplus.

Historical daily climate data was generated from Datadrill (Jeffrey et al. 2001) and AusFarm was run from 1 January 1960 to 31 December 2005; data from 1 January 1966 to- 31 December 2005 was used for this research. This time period was selected to fit with the time frames that were used in the Sustainable Yields project (see 2.2). The atmospheric $\mathrm{CO}_{2}$ levels in AusFarm were set at $360 \mathrm{ppm}$.

A mid-range emission scenario was used to represent climate change. Projected daily climate data was developed using an equivalent method to CSIRO (2008). The Global Climate Model (GCM) ensemble was drawn from the World Climate Research Programme's (WCRP's) Coupled Model Intercomparison Project phase 3 (CMIP3) multi-model dataset archive as monthly data for the period 1960-2005 and interpolated to a $5 \mathrm{~km}$ grid across South Eastern Australia. To create a daily timestep a temporal scaling assumption for temperature, radiation and evaporation was used, where monthly change patterns were applied to the baseline climate timestep as anomalies. For rainfall, monthly change factors were determined for both the percentage change and number of rain days. Evaporation was calculated using a standard temperature-radiation method (Morton 1986). The resulting projected daily climate data being for a 40-year period centered on 2030, with a $+0.6^{\circ} \mathrm{C}$ annual mean temperature change and a $-35 \mathrm{~mm}$ change in mean annual rainfall-potential evaporation. The atmospheric $\mathrm{CO}_{2}$ levels in AusFarm were set at $455 \mathrm{ppm}$.

Incorporating the APSIM rice module into AusFarm was commissioned to the GrazPlan team at CSIRO Agriculture. Associated management decisions for rice were then developed (e.g. irrigation scheduling, ponding and harvesting) and incorporated into the AusFarm modelling framework.

\subsection{Validation of models}

A steering committee was initiated and consulted regularly to develop the underlying assumptions for this body of work. The committee consisted of local agricultural specialists from Murray Local Land Services (MLLS), a local representative of the Rural Financial Councilor Service (RFCS), NSW DPI Technical Specialist in livestock management and a local Agricultural Business consultant whom was also a famer and board member of Murray Irrigation Limited (MIL).

Once the assumptions were developed, they were incorporated into the biophysical model and economic module. Model output was then carefully assessed by the steering committee to ensure the results were within the ranges typically obtained in the MIL region. This process involved numerous model refinements to ensure that the models performed acceptably. This level of acceptability testing, as opposed to formal validation where independent measures are used (Harrison 1990), is typical practice in studies where the aim is to assess the sensitivity of a farming system to an external shift; like a shift in climate variability.

\subsection{Irrigation allocation sequence}

Water allocation data was obtained from the research undertaken by the CSIRO Murray Darling Basin Sustainable Yields Project (CSIRO 2008). This project provides information on current and likely future water availability in the Murray Darling Basin (MDB) including projected allocations for 18 regions including the Murray River and its tributaries under various scenarios. Modelled water allocations considered assumptions around land use, small farm dam conditions and the modelling of river systems, weirs and licence entitlements represented in the state agency's models at the time. The sequence was derived from the Murray Darling Basin Commission's river modelling suite MSM and BigMod using historical daily rainfall and potential evapotranspiration (PET) rates from Silo's Data Drill (CSIRO 2008). 
Broadfoot et al., Building responsive bio-economic models...

This study used the Murray Darling Basin Sustainable Yields Project Scenario A for the baseline allocation sequence, using data from the 1960-2005 period. For the projected water allocation sequence (centered on 2030), Scenario $C$ with medium emissions scenario was used. This resulted in the likelihood of receiving full irrigation allocation from $83 \%$ of year of the historical climate period to $62 \%$ of years for the projected climate period (data not presented). Data was presented as a monthly allocation percentage and incorporated into AusFarm as a matrix (month over time).

\subsection{Water market price function}

A water market price function was developed to allow management decisions to be implemented based on the cost to purchase temporary water. To derive a temporary water price function, nominal temporary water prices were deflated into real prices using 2017 as the base year. Deflated real prices were then detrended (assuming a linear model) to enhance the observation of seasonal (monthly) price movements. Monthly indexes for water prices where then derived using the mean of each water year as the base (a water year assumed to be over the period of July to June). The derived monthly temporary water price indexes were then plotted against their respective water months (July being water month 1, August being water month 2 and so on) and general security water allocation levels. Using least-squares regression a polynomial function was fitted to the data to define the temporary water price index function. This function was then used to define the monthly water price index for any level of modelled water allocation used in the modelling (both historical or projected allocations) and multiplied against an assumed base price. In this study, a temporary water base price of $\$ 140 / \mathrm{ML}$ was used, which represents the 5-year average real price of temporary water in the region and reflects the perceived economics of water use in the region (see 2.7). The derived water price was incorporated into AusFarm as a matrix (month over time).

\subsection{Water Market Tools}

Three scenarios were used to assess the different water market tools used in the MIL region. The three scenarios are: (1) no utilisation of water market tools with reliance on yearly water allocation alone (Allocation); (2) utilisation of yearly water allocation and the ability to carry over unused water into the following water year $($ Allocation $+\mathrm{C}$ ); and (3) utilisation of yearly water allocation, the ability to carry unused water over and the option to purchase water on the temporary water market (Allocation $+\mathrm{CT}$ ).

\subsection{Irrigation management decisions}

\section{Water Balance}

The volume of available irrigation water within each water year (July to June) was calculated from a rolling monthly farm irrigation water balance. Generally, the water balance was added to by water inputs and reduced by on farm water use. For the Allocation scenario the water balance was calculated as total water allocation available minus any use of the water allocation. For the Allocation $+\mathrm{C}$ scenario the water balance was calculated as total water allocation available plus carry over water allocation minus the amount of water allocation used for irrigation. For the third scenario, Allocation $+\mathrm{CT}$, water balance was calculated as total water allocation available plus carry over water allocation plus the purchase of temporary water minus the amount of water allocation used for irrigation.

\section{Water resource decision logic}

Key decision points for the farming system were linked to the farm water balance. Software script was developed to enable the modules in AusFarm to cross reference the farm water balance and make resource allocation decisions which mimicked management decision processes common for the region (Figure 1).

Decision point one (August) coincided with the spring irrigation of the winter crops. The winter crops were irrigated on a set date only if water allocation was available (calculated to be $0.5 \mathrm{ML} /$ ha for each winter crop). For all scenarios, canola was given first preference to available water due to its higher value and water sensitivity.

Decision point two (late September to early October) determined whether the summer rice crop was sown. This decision was based on current water allocation minus the estimated crop water demand for the season. Estimated crop water demand was calculated to be $8 \mathrm{ML} /$ ha of rice to meet the crop's water requirements to January. If the estimated crop water demand was greater than the current water allocation, the rice crop was not sown (for Allocation and Allocation $+\mathrm{C}$ ). For Allocation $+\mathrm{CT}$, an additional decision could be made which allowed for the purchase of temporary water from the water market if a) the water allocation was insufficient to meet projected demand, and b) the price of the temporary water was below \$120/ ML. If the rice crop was 
sown, irrigation water was applied to meet the needs to the crop until the available volume of water was exhausted (for both Allocation and Allocation $+\mathrm{C}$ scenarios). For Allocation $+\mathrm{CT}$ only, if the available water volume was exhausted during the irrigation period, additional water was 'purchased' from the temporary water market regardless of the price. For all scenarios, any water remaining in the water balance at the end of the rice irrigation period was made available to the winter cropping program.

Decision point three coincided with the autumn irrigation of the winter crops. Canola crops were sown in April and wheat was sown in May to mid-June. Crops were irrigated from the water allocation only if it was available. For all scenarios, canola was given first preference to available water. Additionally, for Allocation $+\mathrm{CT}$, if the available water volume was insufficient to meet the demands of the canola crop, water for canola could be 'purchased' from the temporary water market if the price was below the set threshold of \$150/ML.

Decision point four was only implemented for Allocation+CT. Each June, before close of the water year, the water balance could be added to by purchasing water from the temporary water market, for use in the following year. Water was purchased if the temporary water market price was below $\$ 90 / \mathrm{ML}$.

All current water market purchasing and carry over constraints were implemented in the model, being 1) water allocation carry over limit was set at a maximum of $50 \%$ of the entitlement, and 2) water allocation carry over could not exceed a maximum volume of $110 \%$ of entitlement (Murray Irrigation 2014).

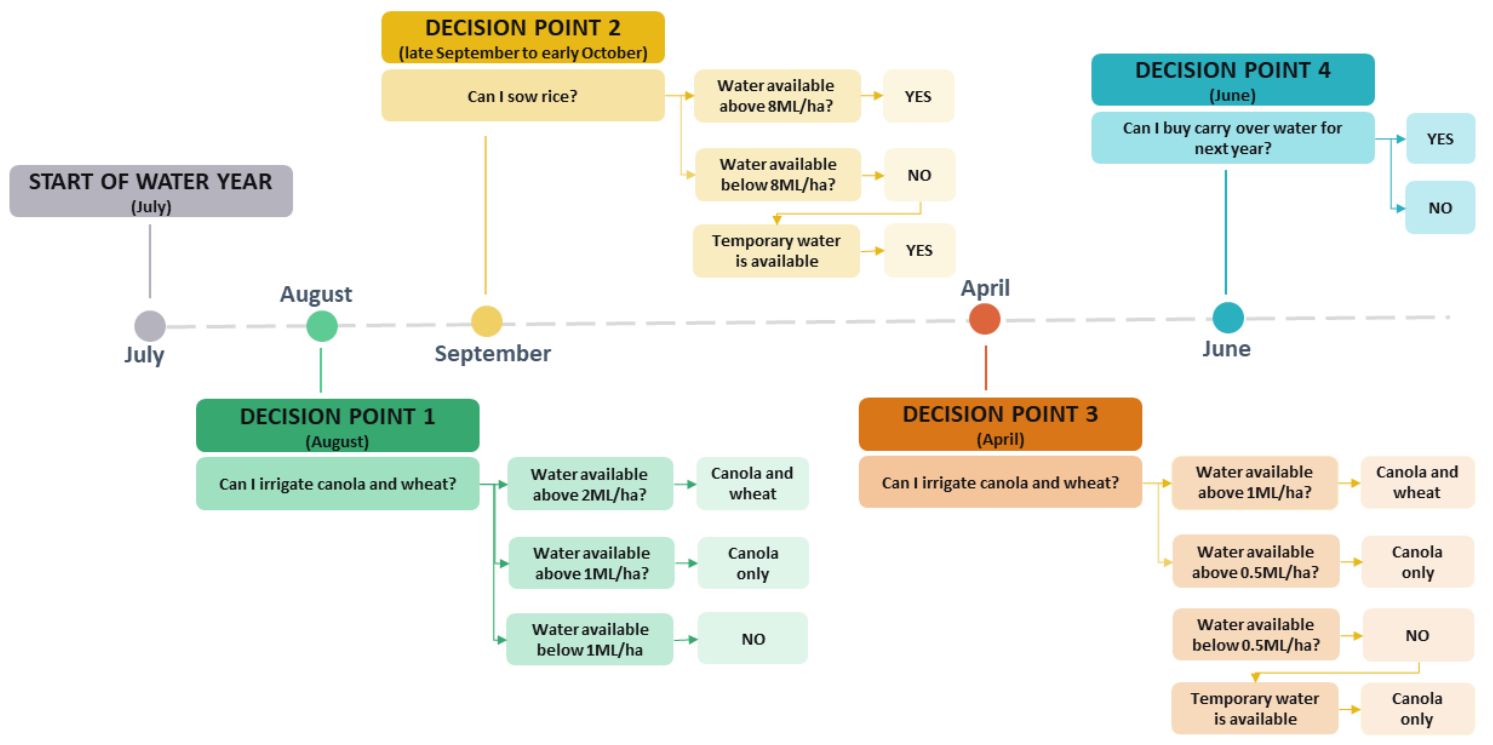

Figure 1. Description of the water resource decision logic used at key decision points.

\section{RESULTS}

The three water market tool scenarios had varying effects on the biophysical performance of the farming system. Analysis of the data reveals that opportunities to sow rice varies between scenarios. When comparing scenarios in the historical climate period, rice was sown in $78 \%$ of years for Allocation, $85 \%$ of years for Allocation $+\mathrm{C}$ and $88 \%$ of years for Allocation $+\mathrm{CT}$. For the projected climate period, rice was sown in $55 \%$ of years for Allocation, $68 \%$ of years for Allocation $+\mathrm{C}$ and $75 \%$ of years for Allocation $+\mathrm{CT}$ (Figure 2).

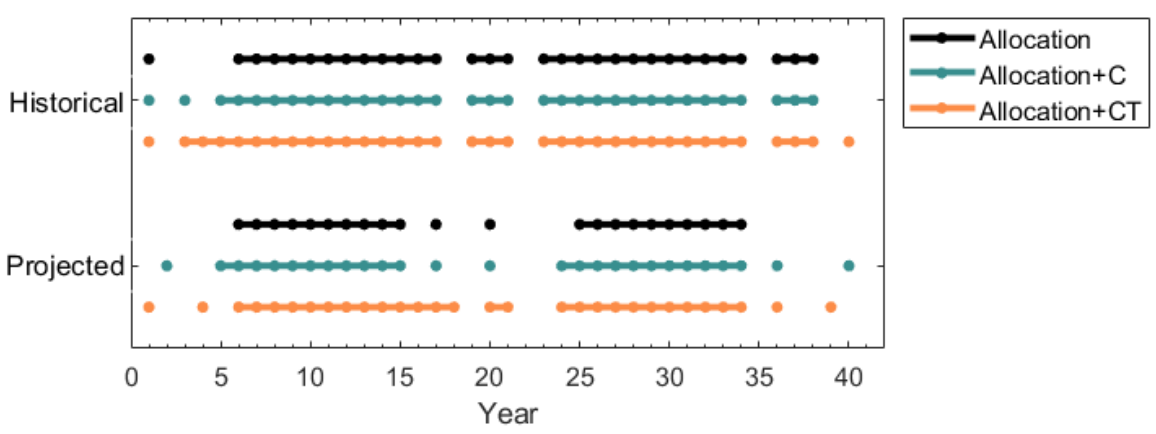

Figure 2. Occurrence of rice sowing events for two climate periods for the three scenarios. Black line is Allocation, teal line is Allocation $+\mathrm{C}$ and orange line is Allocation $+\mathrm{CT}$. 
Of the opportunities to sow rice, the likelihood of a failed crop (assumed a failed crop when yield was below $6 \mathrm{t} / \mathrm{ha}$ ) varied between scenarios, where the rice crop was more likely to succeed if Allocation $+\mathrm{CT}$ was available (Figure 3). For example, at years 33 and 34 in Figure 3b (projected climate), rice was sown in all three scenarios, however, both Allocation and Allocation $+\mathrm{C}$ returned low yields which in real life terms would be considered a failed crop. Additionally, there is one clear occasion in the historical climate where Allocation+CT enabled rice to reach potential yield, whereas it failed under the other two scenarios (i.e. year 21).

The time period between rice sowing events is different between scenarios (Figure $2 \& 3$ ). When comparing scenarios in the historical climate period, the longest time period between rice crop sowing opportunities was 4 years for Allocation, and 1 year for both Allocation $+\mathrm{C}$ and Allcoation $+\mathrm{CT}$. For the projected climate period, there were three instances where the gap between sowing opportunities was 4 years or greater for Allocation, two instances where the gap was three years for Allocation $+C$, and the biggest gap was two years (occurring twice) for Allocation $+\mathrm{CT}$.
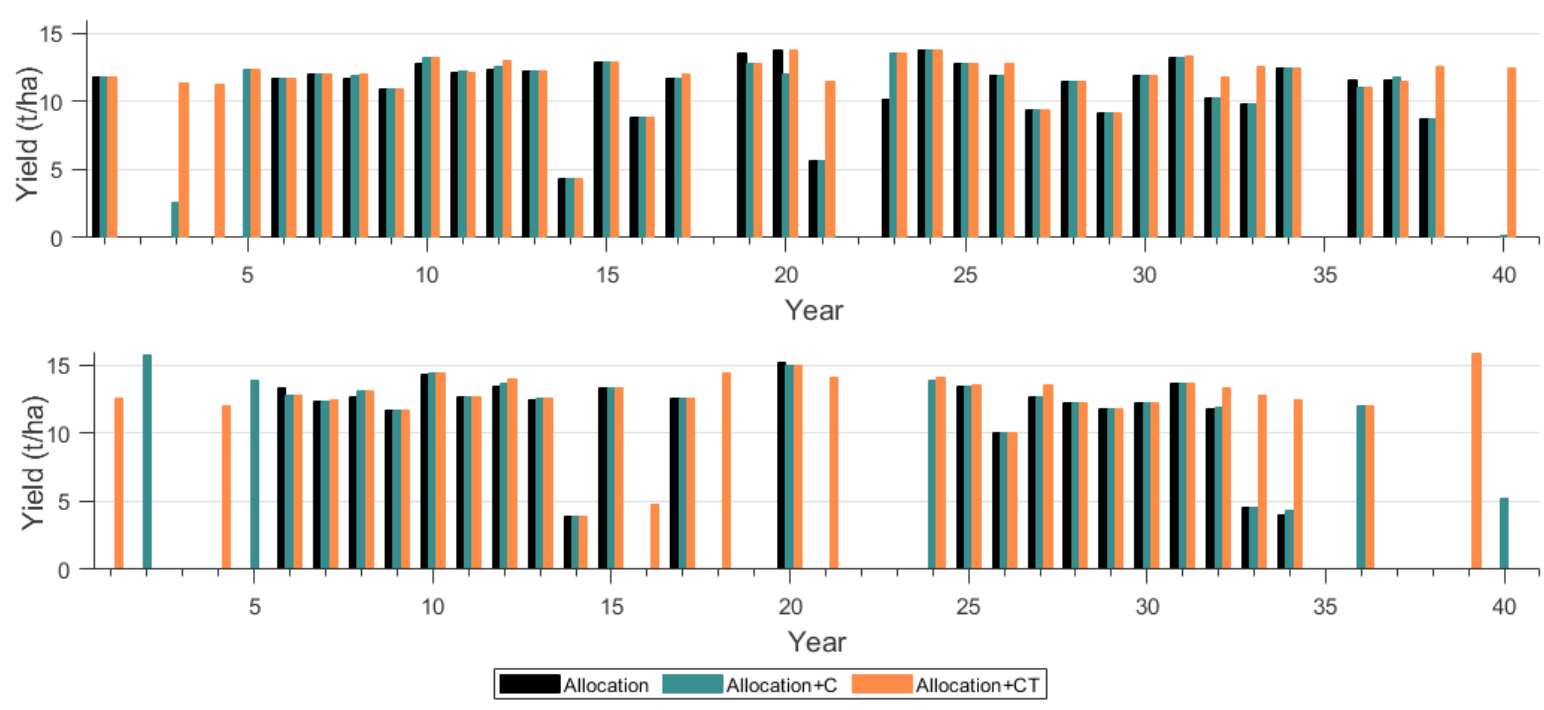

Figure 3. Modelled rice yield ( $\mathrm{t} / \mathrm{ha}$ ) over 40 years for the historical (top) and projected (bottom) climate periods for the three scenarios. Black bar is Allocation, teal bar is Allocation $+\mathrm{C}$ and orange bar is Allocation $+\mathrm{CT}$.

\subsection{Discussion, conclusions and recommendations}

This paper presents a component of work from a broader study that used AusFarm to simulate farm management decisions for an irrigated mixed farming system. By incorporating a complex economic module into the model which allowed for water market tools to be incorporated into the decision framework, the study provided new insights into how these water market tools can offset or mitigate the impacts of future climate (ie. reduced water availability).

The modelling has demonstrated the importance of access to temporary and carry over water to maximise the number of years the summer rice crop can be successfully grown in the region. Ongoing access to these water management tools in the MIL will be key for irrigators to manage future water supply and demand risk. The findings are consistent with those of related research (Loch et al. 2013) which have highlighted the important role of water markets in climate change adaptation.

This paper presents the initial analysis of a wider body of work conducted by the authors, which examined the how the water market tools influence the whole farming system's economic performance (including the winter cropping component of the system). Additionally, the model developed will now enable a range of avenues to extend the work now that the core modelling framework has been developed. Areas for consideration include investigating the spatial impact of current and alternative water policies (e.g. the rules relating to carry over volume and timing of allocation announcement) and establishing new basin-wide water allocation scenarios that are required to update climate change impact and adaptation assessments across the Murray Darling Basin. For instance, this could involve updating of the CSIRO Sustainable Yields analysis using the CMIP 5 GCM suite (Taylor et al. 2012) with a broader range of emissions scenarios (RCPs), and an alternative method of downscaling. 
Broadfoot et al., Building responsive bio-economic models...

\section{Acknowledgements}

The project was funded by Murray Local Land Services through the Australia Government's National Landcare Program. The authors wish to thank the valued contributions from the project steering committee, the NSW DPI Water group who assisted in securing access to the irrigation allocation sequence (a legacy of their partnership with CSIRO in the 2008 Sustainable Yields Project), Neville Herrmann from the GrazPlan team in CSIRO Agriculture for his ongoing support, guidance and development of the rice module into AusFarm which will be a legacy for future work, Murray Irrigation Limited for providing historical water allocation and trading data which enabled the temporary market water price function to be developed.

\section{REFERENCES}

CSIRO, 2008. Water availability in the Murray, A report to the Australian Government from the CSIRO Murray-Darling Basin Sustainable Yields Project. 217pp. CSIRO, Australia.

CSIRO, 2013. Australian Soil Resource Information System. CSIRO/Australian Government Department of Agriculture, Fisheries and Forestry. Available at: www.asris.csiro.au/index.html

Freer, M., Moore, A.D., Donnelly, J.R., 1997. GRAZPLAN: Decision Support Systems for Australian grazing enterprises-II. The animal biology model for feed intake, production and reproduction and the GrazFeed DSS. Agricultural Systems 54, 77-126.

Harrison, S.R., 1990. Regression of a model on real system output: An invalid test of model validity. Agricultural Systems 34, 183-190.

Jeffrey SJ, Carter JO, Moodie KB and Beswick AR (2001). Using spatial interpolation to construct a comprehensive archive of Australian climate. Environmental Modelling \& Software 16, 309-330.

Keating, B.A., Carberry, P.S., Hammer, G.L., Probert, M.E., Robertson, M.J., Holzworth, D., Huth, N.I., Hargreaves, J.N.G., Meinke, H., Hochman, Z., McLean, G., Verburg, K., Snow, V., Dimes, J.P., Silburn, M., Wang, E., Brown, S., Bristow, K.L., Asseng, S., Chapman, S., McCown, R.L., Freebairn, D.M., Smith, C.J., 2003. An overview of APSIM, a model designed for farming systems simulation. European Journal of Agronomy 18, 267-288.

Loch, A., Wheeler, S., Bjornlund, H., Beecham, S., Edwards, J., Zuo, A., Shanahan, M., 2013. The role of water markets in climate change adaptation. 142pp. National Climate Change Adaptation Research Facility, Gold Coast.

McCown, R.L., Hammer, G.L., Hargreaves, J.N.G., Holzworth, D., Huth, N.I., 1995. APSIM - An agricultural production system simulation model for operational research. Mathematics and Computers in Simulation $39,225-231$.

Moore, A.D., Donnelly, J.R., Freer, M., 1997. GRAZPLAN: Decision support systems for Australian grazing enterprises. 3. Pasture growth and soil moisture submodels, and the GrassGro DSS, Agricultural Systems $55,535-582$.

Moore, A.D., Holzworth, D.P., Herrmann, N.I., Huth, N.I., Robertson, M.J., 2007 The Common Modelling Protocol: A hierarchical framework for simulation of agricultural and environmental systems. Agricultural Systems 95 (1-3), 37-48.

Morton, F.I., 1986. Practical estimates of lake evaporation, Journal of Climate Applications and Meteorology $25,371-387$.

Murray Irrigation, 2014. Carryover - The Basics. Murray Irrigation. Available at https://www.murrayirrigation.com.au/wp-content/uploads/2018/05/Fact-Sheet-Carryover-The-Basics.pdf.

Taylor, K.E., Stouffer, R.J., Meehl, G.A., 2012. An Overview of CMIP5 and the experiment design. Bulletin of the American Meteorological Society 93, 485-498. 